\section{THE DEVELOPMENT AND EVALUATION OF AN AUSTRALIAN CHILD PEDESTRIAN SAFETY CAMPAIGN}

Clare Murray, Ioni Lewis, Alexia Lennon, Kim Vuong, Narelle Haworth. Queensland University of Technology, CARRS-Q, Australia

\subsection{6/injuryprev-2016-042156.526}

Background Road crossing is a complex activity and children's risk of pedestrian crashes is greater due to their underdeveloped perceptual and cognitive skills.

This project involved the design and evaluation of a child pedestrian safety campaign, guided by an Extended Theory of Planned Behaviour. The evaluated component consisted of a short $(30 \mathrm{sec})$ video that sought to raise parental road safety awareness and deliver the safety message that parents should hold children's hands in carparks and while crossing the road.

Methods 400 parents of children 3-9 years responded to an online survey. Parents were randomly assigned to either Intervention ( $\mathrm{n}=200)$ or Control $(\mathrm{n}=200)$ groups. Both groups received the same attitudinal and demographic questions. Intervention parents also viewed a $30 \mathrm{sec}$ safety message video and received questions about message interpretation, acceptance, and intentions to perform the suggested behaviour (holding hands).

Results Following one-off exposure to the video, though not statistically significant, the Intervention group reported stronger intentions to hold their child's hand when crossing a road $(\mathrm{M}=4.78, \mathrm{SD}=0.55)$, or in a carpark $(\mathrm{M}=4.73, \mathrm{SD}=0.63)$ in the coming month, than parents in the Control group $(\mathrm{M}$ 4.71, $\mathrm{SD}=0.62$ and $\mathrm{M}=4.72, \mathrm{SD}=0.54$ respectively). Also, the Intervention group reported higher levels of Perceived Behavioural Control (roads, $\mathrm{M}=4.63, \mathrm{SD}=0.55$; carparks, $\mathrm{M}=4.65, \mathrm{SD}=0.57$ ) than parents in the Control group (roads, $\mathrm{M}=4.51, \mathrm{SD}=0.61$; carparks, $\mathrm{M}=4.54, \mathrm{SD}=0.60$ ).

Intervention group parents reported the video was appropriate in content $(\mathrm{M}=4.39, \mathrm{SD}=0.74)$ and tone $(\mathrm{M}=4.19$, $\mathrm{SD}=0.80)$, and that they were likely to adopt the strategy presented $(M=4.20, S D=0.96)$, which they reported as effective $(\mathrm{M}=4.04, \mathrm{SD}=0.92)$.

Conclusions Although parental intentions were high in both groups, these findings provide some support for the persuasiveness of the campaign video. Intervention group parents reported consistently higher intentions to hold their children's hands, and believed that this strategy was something that they could enact easily. The implications of these findings on future research and practice for child pedestrian safety are discussed.

\section{A ONE YEAR STUDY OF ROAD TRAFFIC DEATHS AND INJURIES IN QATAR TO GUIDE POLICIES TO REDUCE MORTALITY AND MORBIDITY}

1,2Lawrence Tallon, ${ }^{2}$ Rafael Consunji. ${ }^{1} /$ mperial College London, UK; ${ }^{2}$ Hamad Medical Corporation, Qatar

\subsection{6/injuryprev-2016-042156.527}

Background Even though Road Traffic Injury [RTI] death rates have declined in Qatar, ${ }^{1}$ they remain three times higher than Western European countries and are the leading cause of death. ${ }^{2}$ This study will collect and analyse key sources of RTI data from Hamad Medical Corporation [HMC], the main national healthcare provider, to better define RTI epidemiology and make policy recommendations for national road safety priorities in Qatar.

Methods A retrospective analysis of RTI data from three important sources of health sector data: the HMC Ambulance Service, major Emergency Department [ED] and trauma registry was conducted for a 12-month period in 2013-14. Standard measures of central tendency were computed and comparisons were made by age, gender, nationality and relative risk.

Results 13,000 patient episodes were collected, summarised and analysed: 10,063 ambulance transportations, including 867 trauma patients, and 2,963 other ED visits. The results identify the key demographic, temporal and geographical features of this public health emergency. Indigenous Qatari males aged 15-19 have a relative risk of RTI 8-11 times higher than the general population and those aged 20-24 have a relative risk 6-9 times higher. RTIs in those aged 25 and above are overwhelmingly in non-Qataris and vary substantially in type of road use between the other Arabic and South Asian residents of this heterogeneous population. The results identify temporal, seasonal and cultural effects associated with RTIs and a map of accident "hot spots" by geographical zone.

Conclusions It is possible to identify with a high degree of probability which road users are most at risk of harm, how, when and where. Using predictive data, public policy makers may be able to more effectively target regulatory, technological and behavioural interventions to those most at risk of harm. These interventions should focus on young male drivers, especially indigenous Qatari, and expatriate pedestrians, especially migrant labourers.

\section{REFERENCES}

1 Mamtani R, Al-Thani MH, Al-Thani AA, Sheikh Jl, Lowenfels AB. Motor vehicle injuries in Qatar: time trends in a rapidly developing Middle Eastern nation. Inj Prev 2012 Apr;18(2):130-2. doi: 10.1136/injuryprev-2011-040147. Epub 2011 Oct 12.

2 Consunji RJ, Peralta RR, Al-Thani H, Latifi R. The implications of the relative risk for road mortality on road safety programmes in Qatar. Inj Prev 2015 Apr;21(e1): e105-8. doi: 10.1136/injuryprev-2013-040939. Epub 2014 Jan 28.

\section{WILL GRADUATED DRIVING LICENCING HAVE MIXED RESULTS FOR REDUCING ROAD INJURY? A QUALITATIVE STUDY IN THE UK}

${ }^{1}$ Judith Green, ${ }^{1}$ Rebecca Steinbach, ${ }^{2}$ Nicola Christie. ${ }^{1}$ London School of Hygiene and Tropical Medicine, UK; ${ }^{2}$ University College London, UK

\subsection{6/injuryprev-2016-042156.528}

Background Graduated Driving Licences (GDL) have the potential to reduce injuries in novice drivers, who are at relatively high risk. However, there are concerns that some risk taking behaviour may be exacerbated by restrictions on, for instance, lift giving. Within the UK, a GDL scheme is planned for Northern Ireland (NI), but not other UK countries. We conducted qualitative research with young adults and parents in NI, England and Wales to identify potential impacts of GDL on injury risk to inform a future evaluation.

Methods Group interviews were held with 16 groups of young adults aged 16-21 and 4 groups of parents. A topic guide covered transport mode choices, incentives for learning to drive, experiences of driving/being a passenger, driving outside the system, telematics and potential impact of GDL restrictions.

Results In rural areas, cars remain essential for accessing work and study for young adults, and for providing spaces to socialise. Restricting provision of lifts for peers would erode mutual support that was part of informal economies. Risky driving (overcrowding, speeding, driving without a licence) was widely reported, and unlikely to be affected by new restrictions. Drink driving was universally disapproved of. Views on telematics were divided, with some in favour of the likely reduced insurance 